\begin{tabular}{lc}
\multicolumn{1}{c}{ Open Access } & IRJEI, Vol: Vol: 2, Issue: 2, \\
International Research Journal of Education and Innovation & July to September 2021 \\
ISSN (ONLINE): $2710-043$ & DOI: $10.53575 /$ irjei.3-v2.2(21)16-21 \\
ISSN (PRINT): $2710-0448$ & http://www.irjei.com \\
\hline
\end{tabular}

\title{
Knowledge Management Practices at University Level in Pakistan
}

Sufi Amin*

Dr. Rukhsana Durrani**

Shahji Ahmad ${ }^{* * *}$

\begin{abstract}
Knowledge Management practices aspires to improve organizational performance. In addition, managing knowledge in an educational institution has many benefits such as better decision making, prevent unnecessary replication of resources, avoiding loss of profitable chance and loss of knowledge when staff exits, improving information of researchers, students and managers (Kidwel et al 2001). The main purpose of the present research was to investigate the Knowledge Management Practices at Universities. The main objectives of the study were: to investigate the existing knowledge management practices of teachers at university level and to find out the difficulties regarding Knowledge Management practices at university level. University teachers were the population of the study. Questionnaire was used as research tool. Data was analysed by the help of SPSS (Version, 24). According to the findings of the study, the majority of teachers use various Brainstorming techniques to produce a wide number of possibilities and unexpected ideas in order to discover a solution to a problem. Some people brainstormed on a sheet of paper. Others converse in the Canteen or Dining Hall. For the transfer of tacit knowledge, the majority of teachers used storytelling techniques.
\end{abstract}

Keywords: Knowledge, Knowledge Management, Practices, University Level

\section{Introduction}

In $21^{\text {th }}$ it is very important for teachers to manage the competencies of the knowledge. In this age it is very important the creation and distribution of knowledge in every field of life, especially in education sector. In the process of knowledge management (KM), knowledge transfer from individual to organization. Therefore knowledge management defined in such a way that, it as the systematized management of individuals, technology, process as well as organizational arrangement so as to connect the worth of the organization through the recycle of understanding \& improvement. Such management can be attained by the help of technique of the creation, sharing as well as use of knowledge (Dalkir, 2005).

Quintas (1997), reflected that "KM is the course of meaningfully working knowledge to meet available necessities, to create innovative opportunities as well as to make use of manageable knowledge". The main challenge which is faced into any organization in the field of knowledge management by the help of knowledge management any organization insistently learns, while up-to-date knowledge is professionally incorporated into work practice, that the knowledge is presented when it necessary (Choo, 2000).

From previous few decades a lot of research conducted in the field of knowledge management, because it is an innovative idea. Several governments in the similar time are in development to wake following a chain of challenges that compulsory them to imitate toward fresh practices as well as methods that can contribution them to be reasonable (Michailova

\footnotetext{
${ }^{*}$ Research Fellow, Department of Education, International Islamic University, Islamabad.

${ }^{* *}$ Lecturer, Department of Early Childhood \& Elementary Teacher Education, Allama Iqbal Open University Islamabad.

${ }^{* * *}$ Lecturer, Department of Education, University of Loralai.
} 
\& Nielsen, 2006). Therefore such scenario has been high the requirement for effectual results from the various creativities that involve Knowledge Management in altered administration programs. Knowledge management is a new ideas for numerous government organizations as well as non- governmental organization especially for developing nations (Michailova \& Nielsen, 2006). It is very important for government to increase the budget in the field of knowledge management as well as for sustainable sources, (Liebowitz, 2012; Yin, 2003).

$\mathrm{KM}$ indorses the understanding that carries each and every communication that linking several organizational development practices as well as initiatives under the research (Gray, 2004). To deal with matters, challenges as well as difficulties, complete method delivers organizational management, therefore altering Knowledge Management as a vigorous practice, most eagerly than just an idea which would support Knowledge Management practices to develop a well-organized force concerning collecting organization client facility distribution responsibilities (Stuhlman, 2008).

Therefore the term "knowledge management" gets knowledge in the 1975, by the increasing anxieties of any administrations towards the increasing purpose of knowledge in administrative maintainability. According to Nonaka \& Takeuchi (1995), imitate that the KM as a kind of management's competence, that draws out person's tacit knowledge \& raise it explicit as well as obtainable for each and every staff to develop well organizational enactment. Davenport and Prusak (2000), presented that "KM is working the stable knowledge in the course of a carefully as well as administratively identified practice for obtaining, shaping, relating, distribution, reintroducing as well as supporting both kind of knowledge tacit knowledge as well as explicit knowledge of employees to increase organizational enactment as well as produce significance"(Davenport and Prusak, 2000).

The term knowledge management introduced after 1980, after 1980 the word KM used everywhere in the worlds, the word knowledge management properly seen in educational conferences, books, educational journals, magazines, research studies as well as use this word in numerous works of different authors. According to Wells (1938), expressed that the term KM, elucidate his notion in the World Brain which were agreed to the academic association of the entire of our common knowledge. Therefore, according to World Brain revealed that "an international society \& description of knowledge as well as thoughts" (Wells 1938).

In the early of 1960s the term knowledge management was first time used by Drucker (Drucker 1964), that was imagine for this entire world, that can be definitely relate in an institute in the form of an intranet. In knowledge management the innovative things is that by the help of this we are now skilled to generate rich, collaborative, face-to-face knowledge encounters more or less by the practise of new communication knowledges. Senge (1990), shown that the learning organization are those organization that can study from previous knowledges kept while corporate memory schemes. According to Barton-Leonard (1995) presented the accepted case of Chaparral Steel, as a KM success story. According to Nonaka \& Takeuchi (1995), intended that knowledge is yield in which way, and how to use the knowledge, \& distribution in the organizations as well as how such knowledge subsidize in the distribution of in the age of transformation (Takeuchi, 1995).

In the start of 1990s, the word knowledge management become most popular, as well as the struggle of experts have been maintained through many educational papers, and these 
research works was published in many journals, seminars, conferences \& different key books in all over the world. While now a days, KM has been understood as a requirement for any institutes, because knowledge management change the whole situation of the entire institute, e.g., the developing competitions in all over the world, \& knowledge getting as well as the speed of data. Each and every events comprise KM, that improves knowledge in order to achieve administrative purposes in fronting conservational pressures and continue competition in the global market. Modest improvement can be achieved from significant how to do things as well as most successive into the competence to immediate growth of innovative understanding. Therefore, in the present progressive administrations, knowledge has become the key sustainable good advantage for administrations. It contributes societies with the proficiency to continue \& proliferation the practise of their assets as well as competences. The complete use of the practises of Knowledge base, attached with possible classifieds facilities, opinions, capabilities, improvement \& thoughts which were enable a corporation to contribute struggle most professionally in the forthcoming times. Therefore, the origins of Knowledge management are deeply rooted in the study of knowledge; while it was extremely viable matter since initial time, (Drucker 1993; Turban \& Aronson 2001). While Still, KM as an innovative ideas for research, as well as himself KM is relatively an innovative knowledge that arose in the early 1990s, (Drucker 1993).

Information technology develops in the mid of 1980s to 1990s, while in this time the concentration towards knowledge management also increased by the help of two important resources. These two important resources are: (i) the first source as the growth of information sources for example, Internet \& the World Wide Web, as well as (ii) the second source is the quickening of the rapidity of scientific modification (Hibbard 1997). While according to the up-to-date information technologies, improved entree to information as well as knowledge, developed conceivable, thus it was very important for governments to learn systems to contract with it, as well as competently impact on it in the residence of work (DiMattia \& Oder 1997; Hibbard 1997). With the assistance of these two fundamentals modification, KM comes out in contradiction of a multi-disciplinary situation in the start of 1990s, (Di-Mattia \& Oder 1997).

\section{Objectives}

The main objectives of the study were:

(1) To investigate the current knowledge management practices of teachers at university level.

(2) To find out the problems regarding Knowledge Management practices at university level.

\section{Research Questions}

The main research questions of the study were:

1. What are the current knowledge management practices of teachers at university level?

2. What are the problems regarding Knowledge Management practices at university level?

\section{Research Methodology}

The present study was quantitative and survey type by nature. All the faculty members of the Universities level is the population of the present study. Due to the nature time limit the study 
was limited to faculties of social sciences. Questionnaires was used as research questions having closed ended questions. The questionnaire was validated by the help of expert, according to expert opinion questionnaire was modified and change. The reliability of the instrument was checked by the help of test-retest method. Researcher personally visited and collect the data. SPSS (Version, 24) was used in data analysis. Percentage and frequency was used for data analysis and interpretation as well as data were presented in the tables.

\section{Results}

Table 01 Perceptions of University Teachers regarding Concept of "Knowledge Management"

\begin{tabular}{lccc}
\hline S. No & Statement & Percentage & Frequency \\
\hline 1 & Creation of Knowledge & 5 & 13 \\
2 & Knowledge Storing & 1 & 03 \\
3 & Usage and share of Knowledge & 3 & 8 \\
4 & All of These & 31 & 78 \\
& Total & 40 & 100 \\
\hline
\end{tabular}

Table 1 depicts the Perceptions of university teachers regarding concept of "Knowledge Management". Most of the (78\%) university teachers agreed in the favour all the three statements that university teachers create new knowledge, storing knowledge and share and use knowledge. Thus, it is depicted that majority of the respondents agreed that university teachers cognizant with the concept of Knowledge Management.

Table 02 Perceptions of University Teachers regarding "Brain storming"

\begin{tabular}{lccc}
\hline S. No & Statement & Percentage & Frequency \\
\hline 1 & Using sticky notes & 5 & 13 \\
2 & A flip chart & 6 & 15 \\
3 & A piece of paper & 14 & 35 \\
4 & All of These & 15 & 38 \\
& Total & 40 & 100 \\
\hline
\end{tabular}

Table 2 describes the Perceptions of university teachers regarding concept of "brain storming". Most of the (35\%) university teachers agreed in the favour that university teachers use a piece of paper. (13\%) university teachers agreed in the favour that university teachers use using sticky notes. And (15\%) university teachers agreed in the favour that university teachers use a flip chart. While (38\%) university teachers agreed with all of these. Thus, it is depicted that majority of the respondents agreed that university teachers cognizant about brain storming.

Table 03 Perceptions of University Teachers regarding "Storytelling"

\begin{tabular}{lccc}
\hline S. No & Statement & Percentage & Frequency \\
\hline 1 & Facial expressions & 5 & 13 \\
2 & Tone of voice & 6 & 15 \\
3 & Gestures & 6 & 15 \\
4 & All of These & 23 & 58 \\
& Total & 40 & 100 \\
\hline
\end{tabular}

$=$ International Research Journal of Education and Innovation 
Table 3 represents the perceptions of university teachers regarding "Storytelling". Most of the (58\%) university teachers agreed in the favour all the three statements that university teachers using facial expressions, tone of voice and gestures. Thus, it is depicted that majority of the respondents agreed that university teachers cognizant with storytelling. Table 04 Perceptions of University Teachers regarding "Knowledge Cafe"

\begin{tabular}{lccc}
\hline S. No & Statement & Percentage & Frequency \\
\hline 1 & Canteen/Dining hall as meeting place & 5 & 18 \\
2 & A Knowledge Café & 6 & 03 \\
3 & Any open office & 6 & 48 \\
4 & All of These & 23 & 33 \\
& Total & 40 & 100 \\
\hline
\end{tabular}

Table 2 shows the perceptions of university teachers regarding concept of "Knowledge Cafe". Most of the (48\%) university teachers agreed in the favour that university teachers use any open office. (18\%) university teachers agreed in the favour that university teachers use using a knowledge cafe. While (38\%) university teachers agreed with all of these. Thus, it is depicted that majority of the respondents agreed that university teachers cognizant that university teacher use any open office for Knowledge exchange.

\section{Conclusions}

The majority of faculty members were aware with the notion of knowledge management, according to the data. To find a solution to an issue, the most of faculty members use various Brainstorming techniques to generate a big number of possibilities as well as unexpected thoughts. While some faculty members brainstormed with a sheet of paper. It was also discovered that the majority of faculty members employ the story-telling technique to convey tacit knowledge. For knowledge exchange, the majority of faculty members communicate in any open office. Some faculty members conversed at the Canteen or Dining Hall. The majority of faculty members keep a document repository in order to find the correct information at the right moment through categorization and organisation.

\section{Recommendations}

1. Establish academic networks that help teachers validate and audit their tacit and implicit knowledge.

2. Universities should encourage students, professors, and staff to participate in the exchange of explicit and implicit knowledge. To stimulate the sharing of knowledge, information, ideas, and stimulations, regular problem-solving and idea-sharing meetings could be established.

3. It is necessary to foster a culture of knowledge and information exchange throughout the university's various departments, sections, centres, and institutes. This will not happen overnight, but consistent and frequent support from the authorities will eventually help to establish such a culture. 


\section{References}

1. Barton-Leonard, D. (1995). Wellsprings of knowledge - Building and sustaining sources of innovation . Boston, MA: Harvard Business School Press.

2. Choo, C. (2000). The Knowing Organization: How Organizations Use Information To Construct Meaning, Create Knowledge, and Make Decisions. . New York: Oxford University Press.

3. Dalkir, K. (2005). Knowledge management in theory and practice,Boston, MA. Elsevier.

4. Davenport, T. H. (2000). orking Knowledge: How organizations manage what they know, Boston, MA. Harvard Business School Press.

5. Gray, D. E. (2004). Doing Research in the Real World. London: Sage Publications Hutchinso.

6. Huberman, J. R. (1994). Knowledge Dissemination and use in Science and Mathematics. Journal of Science Education and Technology, 3(1): 27-47.

7. Michailova S, \&. N. (2006). MNCs and Knowledge Management: A Typology and Key Features. Journal of Knowledge Management, 10 (1): 44-54.

8. Michailova S, \&. N. (2006). MNCs and Knowledge Management: A Typology and Key Features. Journal of Knowledge Management, 10 (1): 44-54.

9. Nonaka, I. a. (1995). The knowledge-creating company: How Japanese companies create the dynamics of innovation. Oxford, UK: Oxford University Press.

10. Senge, P. (1990). the Fifth Discipline, New York: Bantam Doubleday Dell Publishing Group Inc.

11. Stuhlman, D. (2008). Knowledge management terms', In Malhan, V. and Shivarama, R. (eds) Perspectives in Knowledge Management. Scarecrow Press.

12. Wells, H. G. (1938). World brain. Garden City, NY: Doubleday, Doran \& Co.

13. Yin, R. K. (2003). Case study research: design and methods. Sage Publications Ltd. 